\title{
TENDÊNCIAS DE REAÇÃO: A FAIXA ETÁRIA CONDICIONA AS CRENÇAS E ATITUDES LINGUÍSTICAS DOS FALANTES?
}

\author{
Dayse de Souza Lourenço
}

\section{RESUMO}

A manifestação da atitude social do indivíduo, no que concerne à sua variedade e às outras, é analisada por um ramo da Sociolinguística, as Crenças e Atitudes Linguísticas. Alicerçada na Psicologia Social, essa teoria utiliza a técnica Matched Guises (LAMBERT, 1975), ou falsos pares, a fim de verificar a percepção dos falantes em relação à sua variedade e à do outro, a presença de estereótipos, a influência da percepção linguística na atribuição de características físicas e pessoais. Posto isso, o corpus dessa pesquisa é constituído por 24 julgadores provenientes das cidades de Curitiba e Londrina, estado do Paraná, sendo 12 pertencentes à faixa etária de 18 a 30 anos e 12 à faixa etária de 50 a 65 anos. Os dados revelaram que os informantes de 18 a 30 anos realizaram mais avaliações positivas e negativas que os informantes de 51 a 70 anos. Em contrapartida, as não respostas foram mais frequentes na faixa etária de 51 a 70 anos. Dessa forma, observamos que os informantes com idade entre 18 e 30 anos apresentam uma atitude mais crítica frente aos diferentes falares.

Palavras-chave: Crenças e atitudes linguísticas. Falsos pares. Faixa etária.

\section{PRIMEIRAS CONSIDERAÇÕES}

A partir da coexistência de falares há, sem dúvida, uma apreciação diante das variedades linguísticas em uso. Esses julgamentos são reflexos da hierarquia dos grupos sociais, consequentemente, há, em todos os contextos, formas consideradas superiores e inferiores. Salientamos, portanto, que os julgamentos acerca da língua são sociais, fundamentados em critérios não linguísticos, de natureza política e social.

Posto isso, um ramo da Sociolinguística, as Crenças e Atitudes Linguísticas, proveniente da Psicologia Social de Lambert e Lambert (1975), analisa a variação linguística a partir dessas relações de prestígio e desprestígio estabelecidas entre os falantes de Curitiba e Londrina. As cidades, apesar de pertencerem ao mesmo estado, apresentam um cenário linguístico bastante diferente, uma vez que Londrina, cidade interiorana, é mais influenciada pelo sul do estado de São Paulo do que por sua própria capital, Curitiba.

Diante desse panorama, visamos compreender as tendências de reação frente às diferenças de falares, observando se a faixa etária do julgador condiciona, e em que medida, as respostas. Assim, objetivamos verificar i) como ocorre a relação valorativa dos falantes para com as variedades e seus representantes, ii) qual a percepção dos falantes de uma dessas cidades em relação à outra e iii) quais as relações de prestígio e desprestígio. 


\section{SEMINÁRIO DE PESQUISA EM CIÊNCIAS HUMANAS - SEPECH \\ Humanidades, Estado e desafios didático-científicos \\ Londrina, 27 a 29 de julho de 2016}

\section{CRENÇAS E ATITUDES LINGUÍSTICAS}

Os estudos de Crenças e Atitudes Linguísticas apresentam os dois termos estreitamente imbricados, o que dificulta abordar um sem remeter ao outro. Nesse sentido, procuramos tratar, primeiramente, os dois termos separados a fim de apresentar uma definição específica para cada um.

Para o psicólogo social Bem (1973, p.13), as crenças pertencem ao eixo cognitivo, uma vez que são "o produto de experiência direta". Os psicólogos sociais, William e Wallace Lambert (LAMBERT; LAMBERT, 1975), explicam que as crenças são componentes das atitudes, ao lado dos pensamentos, ou seja, encontram-se na esfera cognitiva. Já o sociolinguista William Labov (2008, p. 176) afirma que as crenças são "um conjunto uniforme de atitudes frente à linguagem que são partilhados por quase todos os membros da comunidade de fala, seja no uso de uma forma estigmatizada ou prestigiada da língua em questão". E, ainda, para Botassini (2013), as crenças condicionam o comportamento dos indivíduos, e é nesse sentido, principalmente, a ligação com as atitudes linguísticas.

Lambert e Lambert (1975, p. 100) definem atitude como "uma maneira organizada e coerente de pensar, sentir e reagir a pessoas, grupos, problemas sociais ou, de modo mais geral, a qualquer acontecimento no ambiente". Condensando a ideia de vários manuais de Psicologia Social, Rodrigues (1972, p. 397), afirma que atitude é como "uma organização duradoura de crenças e cognições em geral, dotada de carga afetiva pró ou contra um objeto social definido, que predispõe a uma ação coerente com as cognições e afetos relativos a este objeto".

Segundo a concepção mentalista, a atitude é um "estado de disposição, variável que intervém entre um estímulo que afeta a pessoa e sua reação a ele" (LÓPEZ MORALES, 1993, p. 231) e é constituída por elementos afetivos (emoções e sentimentos), cognitivos (crenças e estereótipos) e comportamentais (tendência à reação de determinado modo).

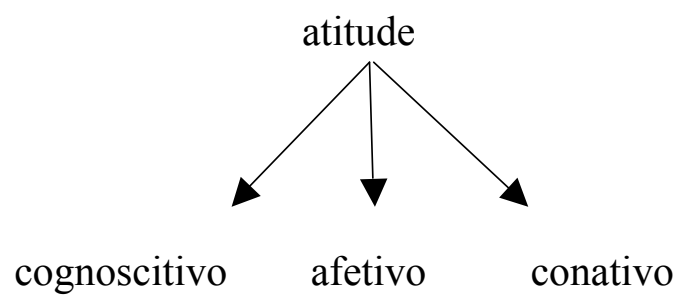

Figura 1 - Os componentes da atitude

Fonte: LÓPEZ MORALES, Humberto. Sociolingüística, 1993, p. 233

Para Lambert (1975), a constituição de uma atitude exige que esses três componentes estejam inter-relacionados de maneira que aquilo que se sente e a forma como se reage frente a um objeto social estejam coerentemente relacionados à forma como se pensa a respeito dele.

Ressaltamos, ainda, que as atitudes exercem influência nos fenômenos de variação e mudança linguística, o que instigou os estudiosos a desenvolverem técnicas para sua medição e quantificação, apesar da dificuldade embutida nessa tarefa, uma vez que as atitudes não são diretamente analisáveis, mas deduzidas. 


\section{SEMINÁRIO DE PESQUISA EM CIÊNCIAS HUMANAS - SEPECH \\ Humanidades, Estado e desafios didático-científicos \\ Londrina, 27 a 29 de julho de 2016}

Nesse cenário, Lambert (1967) desenvolveu a técnica matched guises, ou falsos pares, a qual envolve as reações de ouvintes às gravações de um número de falantes bilíngues lendo uma passagem de dois minutos uma vez em uma de suas línguas (ex.: francês) e, em seguida, uma tradução equivalente da mesma passagem em sua segunda língua (ex.: inglês). Os juízes são levados a ouvir essas séries de gravações e a avaliar as características da personalidade de cada falante bem como possível, usando pistas da voz apenas.

\section{LÓCUS DA PESQUISA: CURITIBA E LONDRINA}

O lócus da pesquisa é constituído por Curitiba e Londrina.

Curitiba, capital do Estado do Paraná, é formada, atualmente, por oito distritos urbanos: Portão, Cidade Industrial, Pinheirinho, Bairro Novo, Cajuru, Boqueirão, Boa Vista e Santa Felicidade. Suas cidades limítrofes são Almirante Tamandaré, Colombo, Pinhais, São José dos Pinhais, Fazenda Rio Grande, Araucária, Campo Largo e Campo Magro.

Segundo o IBGE (2010), Curitiba conta com 1.751.907 habitantes, sua unidade territorial é de $435,036 \mathrm{~km}^{2}$ e o IDHM - índice de desenvolvimento humano municipal - de 0,823 .

O município, centro econômico do estado, é considerado uma das melhores cidades do país para negócios. Altamente tecnológica e industrializada, não conta com atividades agroindustriais para movimentar sua economia. Apresenta ampla rede de préescolas, escolas de ensino fundamental e médio, além de importantes instituições de ensino superior como Universidade Federal do Paraná (UFPR), Universidade Tecnológica Federal do Paraná (UTFPR) e Pontifícia Universidade Católica do Paraná (PUCPR). Curitiba tem, ainda, um dos principais aeroportos do Brasil; um sistema de transporte público considerado um dos melhores do país; museus, teatros, cinemas, shoppings, estádios, parques, bares e uma imensidão de opções para lazer.

Londrina é localizada no Norte do Estado do Paraná, a 387 quilômetros da capital Curitiba. Apresenta uma sede e os distritos de Irerê, Paiquerê, Espírito Santo, Guaravera, Lerroville, Maravilha, Paiquerê, São Luiz e Warta. Seus municípios limítrofes são Arapongas, Apucarana, Assaí, Cambé, Ibiporã, Marilândia do Sul, São Jerônimo da Serra, Sertanópolis e Tamarana.

Segundo o IBGE (2010), Londrina conta com 506.701 habitantes e possui uma unidade territorial de $1.653,075 \mathrm{~km}^{2}$ e IDHM - índice de desenvolvimento humano municipal - de 0,778. A cidade dispõe de uma economia diversificada, abarcando setores industriais, agroindustriais e, sobretudo, comerciais e de serviços. Tem uma ampla rede de pré-escolas, escolas de ensino fundamental e médio, além de importantes instituições de ensino superior, entre elas a Universidade Estadual de Londrina (UEL), Universidade Tecnológica Federal do Paraná (UTFPR) e a Pontifícia Universidade Católica do Paraná (PUC). Tem, ainda, aeroporto, terminal rodoviário, museus, cinemas, shoppings, estádios, parques, bares e várias opções para lazer. 


\title{
XI SEMINÁRIO DE PESQUISA EM CIÊNCIAS HUMANAS - SEPECH \\ Humanidades, Estado e desafios didático-científicos \\ Londrina, 27 a 29 de julho de 2016
}

\section{PROCEDIMENTOS METODOLÓGICOS}

Adotamos, neste estudo, a medição indireta proposta por Lambert (1967), contudo, realizamos algumas alterações na técnica matched guises, falsos pares, a fim de adequar à proposta de observar as crenças e atitudes de curitibanos e londrinenses. Para tanto, contamos com dois leitores naturais das localidades dos dialetos observados, Curitiba e Londrina, para obtermos uma amostra dos falares das duas cidades. Optamos pela escolha de dois falantes com as mesmas características sociais: mesma idade e escolaridade, para que as diferenças diastráticas, diassexuais e diassociais não interferissem no produto da leitura.

Em seguida, realizamos a gravação da leitura, a fim de expressar as marcas fonéticas diferenciadoras dos dois dialetos, como o /r/ em coda silábica e o /e/ átono em sílaba final. Além de conter as marcas fonéticas diferenciadoras dos dois dialetos, o texto selecionado apresenta um tema de cunho científico, expositivo e descritivo para que as atribuições de crenças e atitudes sejam, essencialmente, consoantes à voz/fala e não ao conteúdo.

\begin{abstract}
Foco na firmeza
O novíssimo creme politensor de soja contém um ativo com a proteína do grão que, segundo o fabricante, proporciona um efeito tensor imediato, mas, até aí, a promessa é idêntica à dos outros produtos do mercado. $\mathrm{O}$ grande fator diferencial seria o exclusivo dermo glicídio. Trata-se do açúcar vegetal que age nas fibras da pele para retardar a produção do colágeno, substância responsável pela firmeza dos tecidos. Além disso, o lançamento leva um composto que estimula a renovação celular. Está disponível em versões para diversas faixas etárias, na fórmula diurna e noturna e pode ser encontrado nas farmácias, mercearias e mercados ${ }^{1}$.
\end{abstract}

Apresentamos as gravações aos julgadores. Aos de Curitiba, primeiro o dialeto curitibano e depois o londrinense, em Londrina, na ordem inversa. Aos julgadores, explicamos que o teste funcionaria como quando se atende ao telefonema de um estranho e, automaticamente, atribuímos juízos de valor, imaginando como seria o dono da voz. Imediatamente após ouvirem cada gravação, solicitamos que os julgadores respondessem a uma ficha avaliativa tendo como base a gravação ouvida. Como eram duas gravações, o processo foi realizado duas vezes. Os informantes deveriam dizer se concordavam, ou não, com as afirmações da ficha a respeito da profissão, postura, aparência, caráter, inteligência.

O questionário foi fundamentado nas perguntas utilizadas por Botassini (2013), em sua tese, por sua vez, adaptadas do trabalho de Bergamaschi (2006). É composto por 24 frases, sendo 14 destacando características positivas e 10 negativas, a respeito dos narradores. Os julgadores deveriam responder sim ou não, entretanto, em alguns casos, os julgadores não esboçaram resposta.

Questões

\footnotetext{
${ }^{1}$ Texto adotado por Jacqueline Ortelan Botassini durante a disciplina de Sociolinguística no ano de 2009.
} 


\section{SEMINÁRIO DE PESQUISA EM CIÊNCIAS HUMANAS - SEPECH \\ Humanidades, Estado e desafios didático-científicos \\ Londrina, 27 a 29 de julho de 2016}

1. A pessoa que você ouviu é inteligente?

2. A pessoa que você ouviu é feia?

3. A pessoa que você ouviu é estudada?

4. A pessoa que você ouviu é cuidadosa?

5. A pessoa que você ouviu é grossa?

6. A pessoa que você ouviu é trabalhadora?

7. A pessoa que você ouviu é confiável?

8. A pessoa que você ouviu é responsável?

9. A pessoa que você ouviu é preguiçosa?

10. A pessoa que você ouviu é insegura?

11. A pessoa que você ouviu é antipática?

12. A pessoa que você ouviu é competente?

13. A pessoa que você ouviu é tímida?

14. A pessoa que você ouviu é respeitosa?

15. A pessoa que você ouviu é exibida?

16. A pessoa que você ouviu é autoritária?

17. A pessoa que você ouviu é engraçada?

18. A pessoa que você ouviu é criativa?

19. A pessoa que você ouviu ajuda se alguém precisa?

20. A pessoa que você ouviu sofre preconceito social?

21. A pessoa que você ouviu tem boa cultura?

22. A pessoa que você ouviu tem boa condição financeira?

23. A pessoa que você ouviu tem posto de chefia?

24. A pessoa que você ouviu gosta de falar assim?

Ao responder sim a uma frase que atribui característica negativa, por exemplo “A pessoa que você ouviu é grossa?", o julgador manifesta uma avaliação negativa em relação ao narrador, ao contrário, se a resposta a essa questão for não, é manifestada uma avaliação positiva. Ao responder sim a uma frase que atribui característica positiva, como "A pessoa que você ouviu é estudada?", o julgador avalia positivamente o narrador, enquanto, se o julgador responder não a esta questão, ele expressa uma avaliação negativa.

Quanto ao perfil dos julgadores selecionados, eles deveriam ser nascidos e terem sempre morado na cidade em questão. Ao total, são 24 julgadores, sendo 12 naturais de Curitiba e 12 naturais de Londrina. Quanto à faixa etária, estão estratificados em faixa etária 1,18 a 30 anos, e faixa etária 2, 50 a 65 anos.

Os dados foram tratados por meio do software desenvolvido por Mendez Batista (2012), o qual oferece noções estatísticas simples, como número de ocorrências, porcentagens e cruzamento de variáveis.

\section{ANÁLISE DOS DADOS}

A análise dos dados conta com os resultados estatísticos obtidos por meio do programa desenvolvido por Mendez Batista (2012). Cada um dos 24 informantes respondeu duas vezes o questionário, uma vez relacionada ao seu próprio dialeto e outra 


\section{SEMINÁRIO DE PESQUISA EM CIÊNCIAS HUMANAS - SEPECH \\ Humanidades, Estado e desafios didático-científicos \\ Londrina, 27 a 29 de julho de 2016}

relacionada ao dialeto do outro. Dessa forma, são contabilizadas 48 fichas avaliativas de 24 perguntas, totalizando 1.152 avaliações.

No que concerne à faixa etária, os dados estão expostos na tabela 1 .

\begin{tabular}{lllllll}
\hline Faixa etária & Positiva & \multicolumn{3}{c}{ Negativa } & \multicolumn{2}{c}{ Não resposta } \\
\cline { 2 - 7 } & Quantidade & $\%$ & Quantidade & $\%$ & Quantidade & $\%$ \\
18 a 30 & 366 & 63,5 & 177 & 30,7 & 33 & 5,7 \\
51 a 70 & 349 & 60,6 & 141 & 24,5 & 86 & 14,9 \\
\hline
\end{tabular}

Tabela 1 - Avaliação dos dialetos ouvidos segundo a faixa etária dos julgadores

Fonte: a autora

A tabela 1 traz os dados referentes à faixa etária. Nela, apresentamos a quantidade em números absolutos e o percentual representativo. Ressaltamos que como não resposta estão englobadas as respostas não pertinentes, assim como quando o informante preferiu não responder.

Verificamos que os percentuais são bastante próximos, assim, observamos que a variável faixa etária não indicou diferença significativa no condicionamento das respostas. A caracterização positiva ocorreu em $63,5 \%$ dos casos da faixa etária 1 (18 a 30 anos) e $60,6 \%$ de ocorrência na faixa etária 2 (51 a 70 anos), sendo $3 \%$ de diferença entre elas. As atribuições negativas também obtiveram percentuais pouco díspares, sendo $30,7 \%$ para a faixa etária 1 (18 a 30 anos) e $24,5 \%$ para a faixa etária 2 (51 a 70 anos), sendo $6,2 \%$ de diferença entre elas.

Ressaltamos, ainda, o percentual de não resposta obtido, apenas 5,7\% de casos entre os julgadores da faixa etária 1 (18 a 30 anos), ao passo que $14,9 \%$ dos julgadores da faixa etária 2 (51 a 70 anos) preferiram não responder. Esse dado pode ilustrar que a faixa etária mais jovem tem uma atitude mais crítica frente às variedades, enquanto a faixa etária 2 (51 a 70 anos) se posiciona menos.

Fato semelhante ocorreu no estudo de Botassini (2013), em que, da mesma forma, os informantes da segunda faixa etária se posicionaram menos, dados que parecem indicar que "os informantes com mais idade são menos severos em seu julgamento" (BOTASSINI, 2013, p. 186).

O gráfico 1 ilustra os dados apresentados.

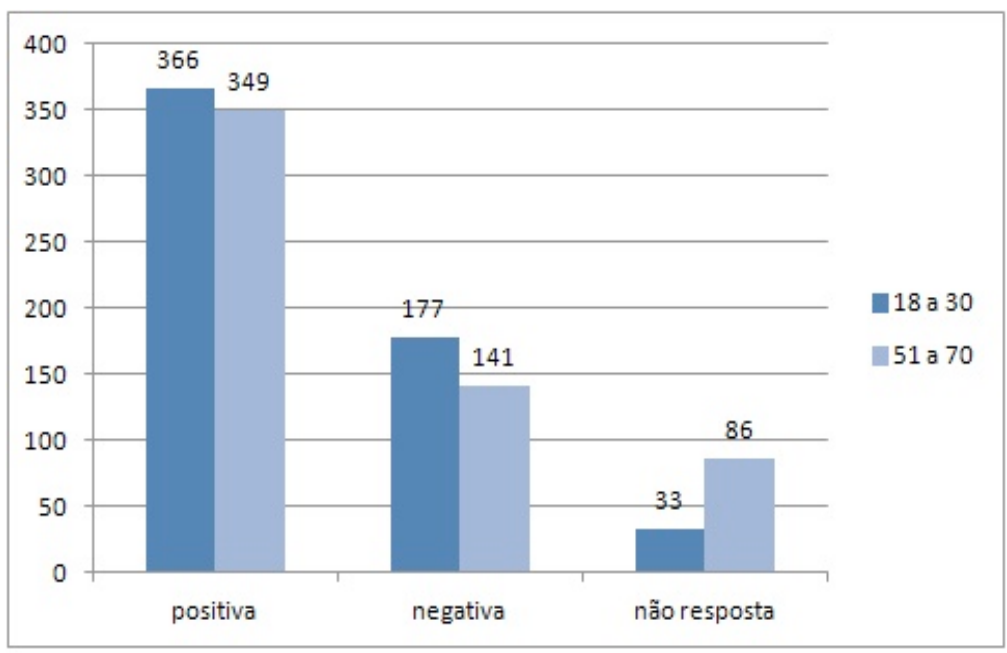




\section{SEMINÁRIO DE PESQUISA EM CIÊNCIAS HUMANAS - SEPECH \\ Humanidades, Estado e desafios didático-científicos \\ Londrina, 27 a 29 de julho de 2016}

Gráfico 1 - Avaliação dos dialetos ouvidos segundo a faixa etária dos julgadores Fonte: a autora

Por meio do gráfico 1 fica mais nítida predominância das atitudes positivas pelos informantes de ambas as faixas etárias, apresentando um total maior que as atitudes positivas e as não respostas somadas. Esses dados permitem afirmar que os informantes tem a tendência a reagir mais positivamente frente às variedades.

\section{CONSIDERAÇÕES FINAIS}

O presente estudo examinou as crenças e atitudes linguísticas de curitibanos e londrinenses em relação à sua variedade e à variedade do outro.

A fim de obter respaldo adequado ao tipo de pesquisa proposta, utilizamos o método de medição indireta - uma adaptação da técnica matched guise. Para que todas as variáveis fossem analisadas de forma confiável, contamos com um programa computacional de análise estatística elaborado por Mendez Batista (2012).

A análise segundo a variável faixa etária dos julgadores revelou que os informantes da faixa etária 1 (18 a 30 anos) realizaram mais avaliações positivas e negativas que os informantes da faixa etária 2 (51 a 70 anos). As não respostas foram mais frequentes na faixa etária 2 (51 a 70 anos). Dessa forma, verificamos que a faixa etária mais jovem tem uma atitude mais crítica frente às variedades.

Ressaltamos, ainda, que formato dessa pesquisa, por ter caráter interpretativista, é suscetível a erros. Isso porque o informante pode se comportar de forma diferente diante do contexto de entrevista do que se comporta, em vias de fato, em meio à sociedade. Contudo, este estudo espera contribuir com as discussões acerca de Crenças e Atitudes Linguísticas, mais especificamente nas localidades observadas.

\section{REFERÊNCIAS}

BEM, Daryl Jay. Conviç̧ões, atitudes e assuntos humanos. Tradução de Carolina Martuscelli Bori. São Paulo: Editora Pedagógica e Universitária Ltda, 1973.

BERGAMASCHI, Maria C. Zandomeneghi. Bilinguismo de dialeto italianoportuguês: Atitudes linguísticas. Rio Grande do Sul. Dissertação. Universidade de Caxias do Sul, Caxias do Sul, 2006.

BOTASSINI, Jacqueline Ortelan Maia. Crenças e atitudes linguísticas: um estudo dos róticos em coda silábica no norte do Paraná. Tese. Universidade Estadual de Londrina. Londrina, 2013.

LAMBERT, Wallace E. A Social Psychology of Bilingualism. In.: Journal of social issues. Vol. XXIII. nº2, 1967.

LAMBERT, William W.; LAMBERT, Wallace E. Psicologia social. $4^{\mathrm{a}}$ ed. Rio de Janeiro, Zahar editores, 1975. 
LABOV, William. Padrões sociolinguísticos. São Paulo: Parábola, 2008.

LOPEZ MORALES, Humberto. Sociolingüística. Madri: Gredos, 1993.

MENDEZ BATISTA, Denerval. Software para codificações automáticas de variáveis e para subsídio ao processo de análise dos dados. Maringá-PR, 2012.

RODRIGUES, Aroldo. Psicologia social. Rio de Janeiro: Editora Vozes, 1972. 